\title{
Effect of SFBT on Anxious Youth
}

\author{
Seema Gupta, Dr. Komal Rai
}

\begin{abstract}
Anxiety is a continuous fear of something bad that may happen. It is one of the common problems. Modernization and urbanization along with the nuclearisation of the family system has lead to an increase the anxiety among everybody especially the youth. The emerging youth are the future of the nation and play a vital role in its development. This is the stage which is neither childhood nor adulthood, is apprehensive of the future and has tendency to develop many fears of the unknown. In India there are very less number of psychotherapists available and lot of people with psychological problems like anxiety do not have access to such services. There is a need of short therapy which can help people solve their problems in short time. This paper attempts to summarize the results of research conducted to see the effect of a short therapy like SFBT on anxiety among the emerging youth. The study was designed with an experimental and control group. 5 participants with mild to moderate anxiety received the solution focused therapy and 5 participants with mild to moderate anxiety were re-administered the anxiety inventory after a gap of about one month. The measuring tool for anxiety used for the study was Beck's Anxiety Inventory. The statistical analysis included t-test of independent sample and repeated measure ANOVA.
\end{abstract}

Keywords: Anxiety, Emerging adults, Experiment, Solution focused brief therapy.

\section{INTRODUCTION}

Emerging adulthood: a term which has originated almost 19 years earlier in 2000 and coined by Arnett [1] reflects the change in the developmental stages with the spread of technology and modernization. When we see through the roles ascribed to the different age groups since earlier times and trace them to the present time, we see a lot difference. For example earlier there was joint family and the eldest male member was the head of the family. But presently the joint family has disintegrated to nuclear family. Earlier the means of communication restricted the person to a limited area. But presently the means of communication is faster than the blink of the eye. Though it may take time to move physically, but virtually the person can communicate with anybody in any part of the world within milliseconds. All these and many more technological advancements on one hand made life quite simple but on the other hand has changed the pattern of interaction and roles of the members. Earlier children were suppose to study and help parents in their day to day activities. Today, there is more stress on education. The parents want their children to concentrate on studies and get good jobs. Now the students are not even allowed to help in the household. They are asked to only study and all the extra work is taken care of by the parents. In this process the students have lost their ability to learn from experience and do anything independently. The parents in their protection has taken away the opportunities of learning through experience and exercise independence. This has made the student or children to be dependent on their parents for longer periods. Even if they study well and get good job, they are not ready to handle the other day to day chores of daily life. This has lead Arnett to name the stage of 18-25 years as emerging adulthood and not adults. Arnett [2] has given following characteristics of emerging adulthood-:

i. This age is age of identity

ii. This age is age of exploration

iii. This age is age of instability

iv. This age is self focused age

$\mathrm{v}$. This is age of mixed feelings

vi. This is age of possibilities

It is almost after completing the education that the youth learn to manage their work independently and so the learning to be adults begins here. Due to the lack of the opportunities to learn from experience and exercise independence, the youth experience anxiety.

\section{ANXIETY}

Anxiety is experienced by the emerging youth in the process of search for their identity in work as well as love. Anxiety is a feeling of nervousness or a fear of what may happen in near future. According to APA, "anxiety as an emotion characterized by feelings of tension, worried thoughts and physical changes like increased blood pressure" [3]. Students since their adolescence are subject to pressure of getting a good job. They are constantly studying and at the same time under the stress that if they do not get job. In country like India, where there is not much guidance available for the career opportunities and where the choice of subjects is decided more on the basis of the social trends than on the capabilities of the child, the experience of stress is even more. These conditions lead to an increased anxiety. A study of medical students has found that 8.67 had mild anxiety, $8.9 \%$ were found to have moderate anxiety and $4.4 \%$ had severe anxiety level [4]. Along with the genetic factors [5, 6, 7, 8] the environmental factors like stress and pressures etc. $[9,10$, $11,12,13$ ] have been found to be responsible for the anxiety. The psychological factors include learnt patterns of behavior through conditioning, imitation etc. [14, 15]. Overprotection at home can also lead to the development of anxiety disorder $[14,16,17,18,19]$. So, there are different possible reasons for the increased anxiety levels. 


\section{SOLUTION FOCUSED BRIEF THERAPY (SFBT)}

The extreme level of anxiety has been found to affect the performance. An optimum level of anxiety is conducive for giving one's best [20]

So, in order to help reducing the anxiety level of people for a healthy mind and body, different therapies are available. Some of the popular therapies for anxiety include:

i. Psychoanalytic therapy of Freud which requires the therapist to explore the past experiences including the childhood experiences to know the cause of the anxiety of the individual. The process of this therapy requires lot of time and may take up to years. The main problem with this therapy is the time required and the dropout rate of the clients.

ii. Existentialism which deals with the concepts of anxiety of existence. It says the reason behind anxiety is the ability to make a choice which leads to uncertainty of whether the choice is right or wrong. This uncertainty is the inherent cause of anxiety. The major drawback of this approach is lack of systematic principles and steps to practice the psychotherapy making it difficult to measure the effectiveness [21]

iii. Person Centered Therapy has also been found to be effective for anxiety [22]. The major drawback is lack of manual or the steps to treatment. The research reported has no untreated control group. These technical problems make this therapy the last choice for treatment.

iv. Behavior Therapy is another popular therapy which works with the basic premise that all behavior is learnt. So, according to the behavioral psychotherapist, the anxiety is also learnt and through the systematic procedures and reinforcement of appropriate behavior, anxiety can be reduced. The major criticism for this approach is that it may change overt behavior but does not change the feelings associated with anxiety, does not provide insight; it treats the symptoms but not cause. These views about the behavior therapy make the therapists' desire for something new.

In this way, the above mentioned therapies along with many other therapies are available to deal with the anxiety level. Though these therapies are able to reduce anxiety but the researchers and therapists are not completely satisfied with any of these and each one of them has their own limitations. In an effort to develop a short therapy, Insoo Kim Berg and de Shazer started experimenting on evidence based Solution focused brief therapy at Milwaukee, BFT Center in 1980's [23, 24, 25]. On the basis of the research done in that center, a manual of the SFBT was developed and this therapy has been found to be quite effective in variety of psychological problems. The SFBT focuses on solutions and not the cause of the problems. It has been found to be helpful to the clients and significant results have been found in 3-5 sessions.

As there is less than 1 psychologist per lakh population in the country, so there is a need to research and adapt short or brief therapies for Indian settings which are economical both in terms of time and money.

\section{DESIGN}

This study is designed to study the effect of SFBT on anxious youth. The population for this study were the college students. They were administered Beck's Anxiety Inventory. The students who were mild to moderate on anxiety were selected and randomly assigned to experimental and control group. Five students were included in experimental group and five in control group. The experimental group was given SFBT by a trained counsellor. After the client was confident the experimental and the control group were again administered the Beck's Anxiety Scale. The pre- and posttherapy scores were pooled. The independent sample t-test was administered to know the significance difference between the experimental and control groups before and after the therapy. The repeated measure ANOVA was used to see the significance of difference before and after the therapy. The results were interpreted according to the norms.

\section{V.RESULTS AND DISCUSSION}

This study was designed to study the SFBT effect on anxious youth. The data collected from the randomly assigned subjects to the experimental and control group was analysed using the statistic in SPSS. The significance of difference of groups before and after the therapeutic intervention was quantified using the independent sample t-test. The statistics are shown below:

\section{Table I Showing Group Statistics}

\begin{tabular}{|ll|l|l|l|l|}
\hline & VAR00009 & N & Mean & $\begin{array}{l}\text { Std. } \\
\text { Deviation }\end{array}$ & $\begin{array}{l}\text { Std. Error } \\
\text { Mean }\end{array}$ \\
\hline BAI & E & 5 & 23.20 & 10.918 & 4.883 \\
& C & 5 & 25.80 & 14.360 & 6.422 \\
& E & 5 & 4.20 & 4.025 & 1.800 \\
& & & & & \\
BAIPT & & & & \\
& C & 5 & 15.60 & 7.092 & 3.172 \\
& & & & & \\
\hline
\end{tabular}

The table no. I shows that there were 5 subjects in the Experimental and Control group before therapy i.e. BAI which stands for Beck Anxiety Inventory. The mean for Experimental group before the therapy was 23.20 and after the therapy it reduced to 4.20. Similarly, the control group mean for first time administration was 25.80 and after a gap of time the mean anxiety score on re-administration was 15.60 . This reflects a difference of only 2.6 before therapy and a difference of 11.4 post therapy scores. To test the whether the difference of 11.4 is significant or not significant, the t-test was applied. The results are shown in Table no. II below. 
Table II Showing the Independent Samples Test

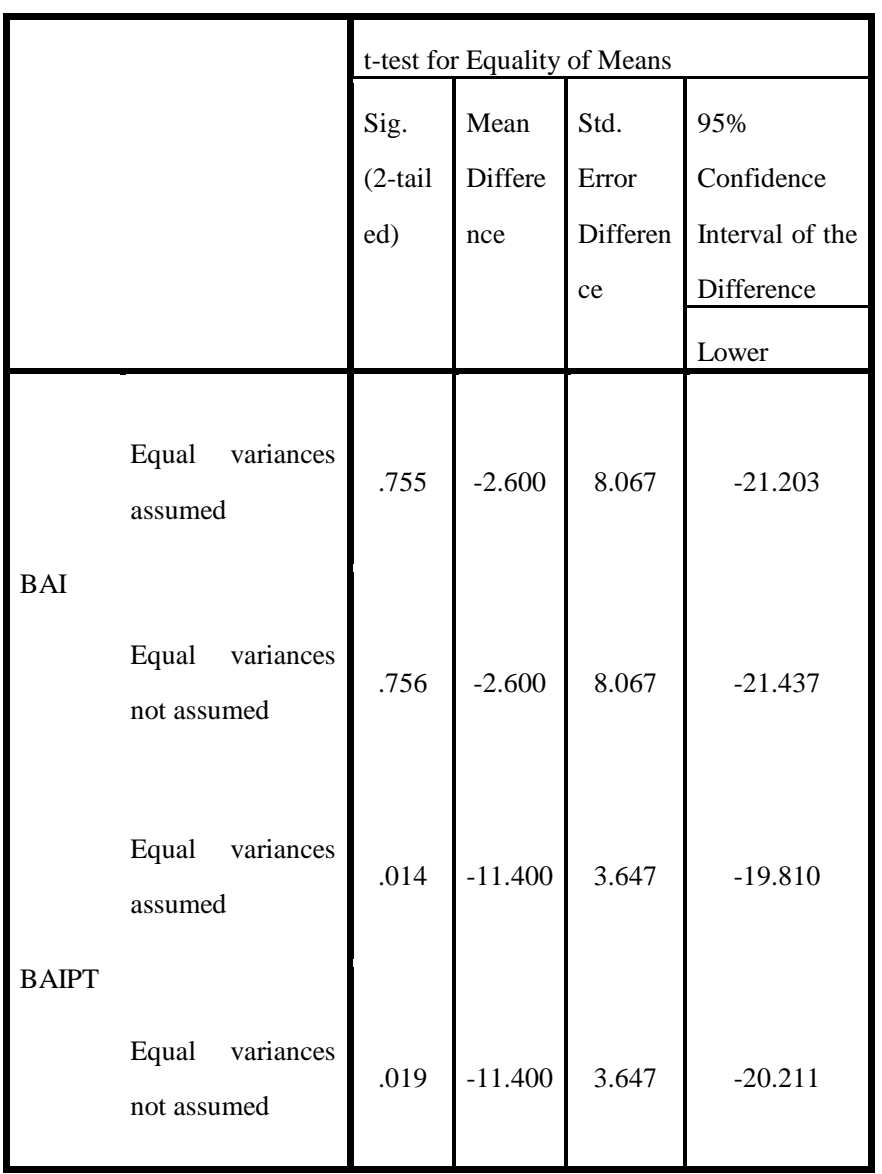

The table no. II shows the value of independent sample t-test as calculated using SPSS. The value of pre- therapy experimental and control group is not significant as the calculated values 0.755 is more than $p=0.05$. The post-therapy experimental and control group value of t-test comes out to be 0.014 which is significant as it is less than $\mathrm{p}=0.05$.

The repeated measure ANOVA was applied to see the significance difference between pre- and post- therapy experimental group. Table no. 3 shows the descriptive statistics for the repeated measures ANOVA of experimental group.

Table no. III Showing the Descriptive Statistics of Experimental Group

\begin{tabular}{|l|l|l|l|}
\hline & Mean & Std. Deviation & N \\
\hline BAIE & 23.20 & 10.918 & 5 \\
BAIPTE & 4.20 & 4.025 & 5 \\
\hline
\end{tabular}

The Table no. III shows that the mean for experimental group before therapy is 23.20 and post-therapy mean of the experimental group is 4.20. To know the significance of difference between these values, repeated measures ANOVA is done as the same subjects have been tested twice. The Table no. IV shows Within-Subjects Contrasts of Experimental group on Anxiety.
Table IV Showing Tests of Within-Subjects Contrasts of Experimental group on Anxiety

\begin{tabular}{|ll|l|l|l|l|l|}
\hline Source time & $\begin{array}{l}\text { Type III } \\
\text { Sum of } \\
\text { Squares }\end{array}$ & df & $\begin{array}{l}\text { Mean } \\
\text { Square }\end{array}$ & F & Sig. \\
\hline $\begin{array}{l}\text { time } \\
\text { Error(time) }\end{array}$ & Linear & $\begin{array}{l}902.500 \\
143.000\end{array}$ & 1 & $\begin{array}{l}902.500 \\
35.750\end{array}$ & 25.245 & .007 \\
\hline
\end{tabular}

The Table no. IV Shows that the F-value comes out to be 25.245 which is significant as the significance is 0.007 i.e. less than $\mathrm{p}=0.05$.

Table V Showing the Descriptive Statistics of Control

\begin{tabular}{|l|l|l|l|}
\multicolumn{3}{|c|}{ Group } \\
\hline & Mean & Std. Deviation & N \\
\hline BAIC & 25.80 & 14.360 & 5 \\
BAIPTC & 15.60 & 7.092 & 5 \\
\hline
\end{tabular}

Table no. $\mathrm{V}$ shows the descriptive statistics of the Control group. It is evident from the table that the mean of first administration of Beck's Anxiety Inventory comes out to be 25.80 and on the re-administration after a gap of some time is 15.60. To test the significance of difference of mean 10.2, repeated measures ANOVA using SPSS was done. Table no. VI Shows the Tests of Within-Subjects Group of Control Group on Anxiety.

Table VI Showing the Tests of Within-Subjects Group of Control group on Anxiety

\begin{tabular}{|ll|l|l|l|l|l|}
\hline Source time & $\begin{array}{l}\text { Type III } \\
\text { Sum of } \\
\text { Squares }\end{array}$ & df & $\begin{array}{l}\text { Mean } \\
\text { Square }\end{array}$ & F & Sig. \\
\hline time & Linear & 260.100 & 1 & 260.100 & 2.352 & .200 \\
Error(time) & Linear & 442.400 & 4 & 110.600 & & \\
\hline
\end{tabular}

Table no. VI shows the F-value for the control group preand post- gap anxiety scores on Beck's Anxiety Inventory comes out to be 2.342 which is not significant as the significance is more that $\mathrm{p}=0.05$.

From the above results it can be interpreted that the therapeutic intervention with SFBT has produced significant difference in the anxiety levels of the college youth ( from Table no. IV the value is significant). This value cannot be attributed to subject related factors as the subjects of both the groups were not significantly different at the beginning of the experiment (BAIPT score from Table no. II is 0.755 i.e. more than 0.05). These differences cannot be attributed to time related factor as the control group was tested almost after a same gap of time as the experimental group was tested after the therapeutic intervention and there were no significant difference on retesting (From Table no. VI, the significance value is 0.2 which is more than $\mathrm{p}=0.05$ ).

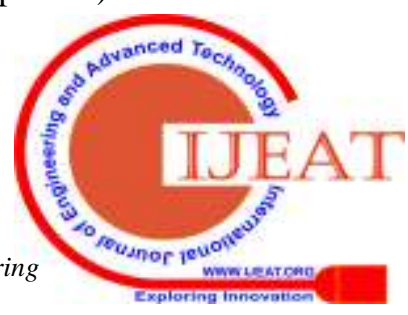


A thorough analysis of the results of this research support solution focused brief therapy as an effective therapy. The average session required for the desired results was three. This is a reasonable time making the therapy economical both in terms of money and time.

Similar results have been reported by other studies. The effectiveness of SFBT has been reported for internalizing disorders [26]; for intellectual disabilities [27]; group therapy with adults on problem control [28]; with group therapy on students with increased self regulation [29].

So, the results indicate SFBT to be an effective therapy. The sample size of this research is small. So, more well designed research with randomized experimental and control groups should be done to make SFBT a popular therapy.

\section{REFERENCES}

1. J. J. Arnett, " Emerging adulthood: A theory of development from the late teens through the twenties.," American Psychologist, vol. 55, pp. 469-480, 2000.

2. J. J. Arnett, Emerging Adulthood: The Winding Road From the Late Teens Though the Twenties, Oxford University Press, 2004

3. "Anxiety," 2017. [Online]. Available: www.apa.org/topics/anxiety/. [Accessed 18 August 2017].

4. V. Prabha, S. Parkash, S. Ravi and I. Vijaynath, "Study of Examination Related Anxiety Levels in First Year Medical Students," International Journal of Physiology, vol. 5, no. 1, pp. 120-123, January-June 2017.

5. D. H. Barlow, S. Sauer-Zavala, J. R. Carl, J. R. Bullis and K. K. Ellard, "The Nature, Diagnosis, and Treatment of Neuroticism: Back to the Future.," Clinical Psychological Science, vol. 2, no. 3, pp. 344-365, 2014.

6. L. A. Clark, "Temperament as a unifying basis for personality and psychopathology [Special issue]," Journal of Abnormal Psychology, vol. 114, pp. 505-521, 2005.

7. H. J. Eysenck, The biological basis of personality, Springfield, IL: Charles, C. Thomas, 1967.

8. J. A. Gray and N. McNaughton, "The neuropsychology of anxiety: Reprise.," in Perspectives on anxiety, panic and fear (The 43rd Annual Nebraska Symposium on Motivation), Lincoln, Nebraska University Press, 1996, pp. 61-134.

9. J. Gelernter and M. B. Stein, "Heritability and genetics of anxiety disorders.," in Oxford handbook of anxiety and related disorders., Oxford, UK, Oxford University Press, 2009.

10. K. S. Kendler, "Reflections on the relationship between psychiatric genetics and psychiatric nosology.," American Journal of Psychiatry, vol. 163, pp. 1138-1146, 2006.

11. M. Owens, I. M. Goodyer, P. Wilkinson, A. Bhardwaj, R. Abbott, T. Croudace and B. J. Sahakian, "5-HTTLPR and early childhood adversities moderate cognitive and emotional processing in adolescence.," PLos One, vol. 7 , no. $11,2012$.

12. M. Rutter, T. E. Moffit and A. Caspi, "Gene-environment interplay and psychopathology: Multiple varieties but real effects.," Journal of Child Psychology and Psychiatry, vol. 47, pp. 226-261, 2006.

13. J. W. Smoller, S. R. Blocks and M. M. Young, "Genetics of anxiety disorders: The complex road from DSM to DNA," Depression and Anxiety, vol. 26, no. 11, pp. 965-975, 2009.

14. D. H. Barlow, Anxiety and its disorders: The nature and treatment of anxiety and panic., 2nd ed., New York, NY: Guilford, 2002.

15. L. Suarez, S. Bennet, C. Goldstein and D. H. Barlow,
"Understanding anxiety disorders from a "triple vulnerabilities" framework.," in Oxford handbook of anxiiety and related disorders, M. M. Anotny and M. B. Stein, Eds., New York, NY, Oxford University Press, 2008, pp. 153-172.

16. B. F. Chorpita and D. H. Barlow, "The development of anxiety: The role of control in the early environment.," Psychological Bulletin, vol. 124, no. 1, pp. 3-21, 1998.

17. O. Dan, A. Sago-Schwartz, Y. Bar-haim and Y. Eshel, "Effects of early relationships on children's perceived control: A longitudinal study.," International Journal of Behavioral Development, vol. 35, no. 5, pp. 449-456, 2011.

18. K. S. White, T. A. Brown, T. J. somers and D. H. Barlow, "Avoidance behavior in panic disorder: The moderating influence of perceived control.," Behaviour Research and Therapy, vol. 44, pp. 147-157, 2006.

19. M. R. Gunnar and P. A. Fisher, "Bringing basic research on early experience and stress neurobiology to bear on preventive interventions for neglected and maltreated children.," Development and Psychopathology, vol. 18, no. 3, pp. 651-677, 2006.

20. R. M. Yerkes and J. D. Dodson, "The relation of strength of stimulus to rapidity of habit-formation.," Journal of Comparative Neurology and Psychology, vol. 18, pp. 459-482, 1908

21. R. S. Sharf, Theories of psychotherapy and counseling: Concepts and cases, 5th ed., Belmont, CA: Brook/Coles, Cengage Learning, 2012.

22. J. D. Bozrath, F. M. Zimring and R. Tausch, "Clinet-centered therapy: The evolution of revolution.," in Handbook of research and practice, D. J. Cain and J. Seeman, Eds., Washington, DC, American Psychological Association, 2002, pp. 147-188.

23. S. de Shazer, Clues: Investigating solutions in brief therapy., New York: Norton, 1988.

24 S. de Shazer, Keys to solution in brief therapy, New York: Norton, 1985.

23. S. de Shazer, Patterns of brief family therapy: An ecosystemic approach, New York: Guilford Press, 1982.

26. E. Schmit, M. Schmit and A. Lenz, "Meta- Analysis of Solution-Focused Brief Therapy for Treating Symptoms of Internalizing Disorders," Counselling Outcome Research and Evaluation, vol. 7, no. 1, pp. 21-39, 2016.

27. J. Roeden, M. Maaskant and L. Curfs, "Effectiveness of solution-focused coaching of staff of people with intellectual disabilities: A controlled study," Journal of Systemic Therapies, vol. 33, pp. 16-34, 2014.

28. E. K. Quick and D. Gizzo, "The " doing what works" group: A quantitative and qualitative analysis of solution-focused group therapy," Journa of Family Psychotherapy, vol. 18, pp. 65-84, 2007.

29 T. Fitch, J. Marshall and W. McCarthy, "The effect of solution-focused groups on self-regulated learning," Journal of College Student Development, vol. 53, pp. 586-595, 2012. 